\title{
Developing the mental health workforce capacity in primary care: implementing the role of graduate primary care mental health workers in England
}

\author{
David Rushforth, Principal Lecturer, Centre for Clinical and Academic Workforce Innovation, University of Lincoln \\ Jit Patel, Business Manager, Centre for Clinical and Academic Workforce Innovation, University of Lincoln \\ Alison James, Workforce Specialist, NIMHE National Workforce Programme, Care Services Improvement \\ Partnership (CSIP)
}

Siobhan Chadwick, Workforce Specialist, NIMHE National Workforce Programme, Care Services Improvement Partnership (CSIP)

\section{Abstract}

The scale of current demand on primary care services from people seeking help with common mental health problems places enormous pressure on the existing front line workers in general practice. The paucity of training opportunities and competing pressures to deliver improved services across a range of general practice targets remains a major challenge for primary care professionals. The impact of government policy, to improve both access to and choice of treatments, has raised public expectations.

The commissioning of the graduate workforce, the graduate worker in primary care mental health (GWPCMH), commenced in 2002, in response to the publication of target numbers detailed in the Priorities and Planning Framework, (DoH, 2002). It signalled a determination to expand the workforce provision and improve the quality of care for service users with common mental health problems.

This paper examines the scale of common mental health problems, the policy response and the commissioning process. Particular attention is given to examining the barriers that have been shown to affect implementation, identifying the key influencers and the resources required to train these workers.

\section{Key words}

graduate primary care mental health worker; mental health policy in primary care; commissioning mental health training

\section{Introduction}

The burden of common mental health problems has grown in the past decade. For example, depression is projected to be the second most common cause of disability, after heart disease, by 2020 (Murray \& Lopez, 1996). In the United Kingdom, estimates based on returns from general health questionnaires estimate that one in four people visiting doctors' surgeries have a mental health problem (Goldberg \& Huxley, 1992). The demands on primary care services are onerous, with $90 \%$ of all patients with mental health problems seeking access to primary care for treatment (DoH, 1999). Mental health problems are the second most common reason for consulting a general practitioner (McCormick et al, 1995) and in $30 \%$ of GP consultations, mental health problems are identified as the main issue (Kendrick et al, 1994).

\section{The readiness of primary care workers to address mental health needs}

While many common mental health problems are minor and transitory, primary health care professionals have traditionally faced considerable difficulty in detecting commonly presenting health problems, such as depression. Fewer than $35 \%$ of general practitioners have undertaken any staff development education relevant to primary mental health (Kerwick et al, 1997).

There is also some evidence that other primary care workers may not always deliver high standards of care for people with mental health problems. Practice nurses encounter particular difficulties and miss up to $77 \%$ of 


\section{Implementing the role of graduate primary care mental health workers in England}

people presenting with depression (Plummer, 1997). This is not surprising given that less than two per cent of practice nurses have undertaken appropriate training to manage the disorder (Crosland \& Kai, 1998). Although there remains a clear imperative to further address the learning needs of primary care workers, the Department of Health recognised that the demands on front line care are such that a new workforce capacity was needed to provide bespoke support to people with mild to moderate mental health problems (DoH, 2001a).

\section{Investment in primary mental health care}

The capacity of secondary mental health to address the huge demand for help is limited by both financial and longstanding recruitment difficulties. Policy initiatives since 2001 have actively encouraged primary care trusts (PCTs) to take a lead role in commissioning and delivering mental health services (DoH, 2001). These policy imperatives have led to legislative changes in the GP general medical services contract, whereby quality indicators lead to financial reward for providing enhanced depression management (NIMHE North West Regional Development Centre, 2004a).

Nevertheless, delivery of enhanced provision pivots upon an attitude change, which first acknowledges that mental health exists within a social and personal context, and is not just a narrow health consideration. Second, such an attitude change accepts that primary care has a duty to address these social and health care needs in general practice settings. This requires the realignment of the current working practices to harness the potential of the GPCMHWs alongside a wider review of referral protocols between primary care and the community mental health teams within the local mental health trusts. The NHS Plan (DoH, 2000) set out a vision of a modernised service that both improves access, and promotes treatment choice. In practice, this has been supported by investment in primary care through the additional workforce capacity provided by GPCMHWs together with guidance on how change can deliver improvements for service users and carers (DoH, 2003).

\section{The policy context}

The NHS Plan for England initially signalled investment in the primary care workforce to support the wider 10-year plan for mental health and social care (DoH, 2000). The graduate primary care mental health workers are one of a number of new roles appointed to complement and expand existing mental health workforce provision as advised by the Workforce Action Team (WAT, 2001).

The Priorities and Planning Framework set out a target to appoint 1,000 of these graduate primary care mental health workers by December 2004, supported by a national mental health delivery plan to monitor performance and review progress managed by the Strategic Health Authorities in England (DoH, 2002). Additional revenue to support their appointment and their training fees were delivered with the uplift in general allocation, on the basis of weighted capitation, to primary care trusts from the financial year 2003/4 (DoH, 2003).

Expansion of the graduate primary care mental health workforce has not been uniform across England with significant local differences emerging (Rushforth, 2004). A number of primary care trusts (PCTs) failed to meet the local target numbers, typically citing competing spending priorities in other target areas. Significantly, where strategic health authorities sent a clear message that primary care mental health worker recruitment was an important performance indicator, workforce targets were achieved. The majority of PCTs have delivered on target numbers and a small but growing number are investing strategically in primary care mental health workers above these targets to build workforce capacity to meet local delivery plans (Rushforth, 2004). The number continues to grow as graduate primary care mental health workers are recruited to second and third cohort to training programmes during 2005/6.

In summary, while all primary care trusts were funded in their baselines to employ two or more graduate primary care mental health workers, in practice the funding was not ring-fenced by the Department of Health. A small number of PCTs cited competing priorities to develop assertive outreach and early intervention teams as a challenge to their budgets. Others were less specific, citing the pressure to balance their financial positions, further undermining their commitment to invest in the recruitment of these workers.

\section{Challenges faced by primary care trusts}

The emergence of graduate workers in primary care mental health has presented fresh challenges to the key agencies involved, most notably the employing primary care trusts. Shifting the Balance of Power (DoH, 2002) 
devolved responsibility for commissioning local mental health service to PCTs, and primary care trusts have struggled with this onerous and complex task. Many have sought policy guidance from the Department of Health.

Subsequently, best practice guidance sought to assist PCTs to implement these targets (DoH, 2003). Others have also signed up to regional collaborations with key stakeholders to understand how best to address recruitment, selection policy and conditions of employment. Progress has been rapid.

The national workforce plan to target graduates to build a capacity of 1,000 additional primary care mental health workers has generated considerable interest from graduates, notably those with a first degree in psychology. Since the introduction of this role, significant numbers of high quality graduates have responded to both local and national job advertisements across England. In all areas applications outstripped the number of posts advertised by a healthy margin with 650 posts filled by December 2004 (Rushforth, 2004). By April 2007 over 900 GPCMHWs had received training (Appleby, 2007).

\section{The pre-commissioning phase}

Trent Workforce Confederation, and latterly the Centre for Clinical and Academic Workforce Innovation (CCAWI) at the University of Lincoln, led on the commissioning of a network of higher educational programmes in England to develop the practice skills of this new graduate workforce. This was supported through workforce development funding from the mental health policy unit at the Department of Health.

In the pre-commissioning phase, practical human resources issues dominated the exploratory discussions. Stakeholders sought clarification of a number of issues pivotal to commit to commissioning of training programmes. While sufficient progress convinced the higher education institutions to tender for primary care mental health worker training monies, many unresolved issues remained, therefore the dialogue continued.

It was acknowledged from the outset that flexible funding streams were a prerequisite to successful implementation and these funds would need to be strategically managed post-commissioning. This distinction sets the primary care mental health training apart from the traditional block commissioning arrangements between the NHS and higher education institutions.

\section{The education and training commissioning process}

In 2002, 14 regional higher education institutional collaborations across England responded to the invitation to tender for funding to support education and training and all attended for interview to present their tender documents and outline curricula in January 2003.

The interviewing panel included service user representation, representatives from Trent WDC, NIMHE workforce programme and Department of Health policy branch. Each of the higher education collaborations submitted tender documents and gave a summary presentation of the outline curricula, followed by a question and answer session with the opportunity for wider discussion. This focused on the following key areas:

- the fitness for purpose of the outline curricula

- the strength of local collaborations

- user involvement in delivery and review of training programmes

- identification of funding to meet the targets for new posts in the PCTs

- the level of tuition fees to support the new training programmes

- the identification and preparedness of line managers and practice supervisors

- the sustainability of student numbers beyond the initial PCT targets

- selection, recruitment and employment rights.

The project management brief emphasised the necessity of thorough local consultation with stakeholders, and a series of visits to the teaching centres across England followed. These meetings sought to brief stakeholders, support local champions, further understanding of barriers to implementation and lobby key influencers, namely local commissioners and occasionally attending PCT finance directors. Subsequently, Trent Workforce Development Confederation (WDC) provided financial support for wider regional consultation exercises, where uncertainty over the viability of the initiative was signalled.

NIMHE regional development centres were well positioned to identify local expertise and co-ordinate steering groups with representation from employing primary care trusts, higher education, user representation, workforce development mental health leads, and the strategic health authorities to examine local implementation issues in detail. 
This funding stream also supported the secondment of experienced practitioners to development centres to act as local champions across targeted strategic health authority areas, again to brief key influencers on a one to one basis. Where this has worked well, employers have worked closely with both HEI programme leads and user groups to recruit to post, agree variation on the baseline tuition fee, and determine the competencies required for practice.

The first wave, postgraduate certificate training programmes enrolled their initial cohort students in January 2004. Twenty-three higher education institutions committed to develop training across England, of which 21 had established training programmes by August 2005 . Difficulty in sustaining minimum recruitment numbers to new training cohorts has been hampered by major financial difficulties encountered by PCTs, who having achieved target numbers were reluctant to fund additional GPCMHW posts. This led to the temporary suspension of many training programmes. In the academic year 2006-7, only seven higher education institutions were running the postgraduate certificate programme.

The North West Development Centre in their role as the primary care lead for NIMHE, co-ordinated a network of key stakeholders to address these strategic, design and implementation issues. A national conference sought to initiate a learning process and disseminate good practice in recruitment, selection and training and provide a platform to report on findings of regional and national research. The distillation of this work was published in a practical guide in September 2004, which details advice on HR employment practices and provided exemplars of collaborative working. This guide has been widely disseminated through regional development centre networks and mental health workforce development leads (NIMHE North West Development Centre, 2004b).

In parallel, the Trent WDC, and latterly CCAWI, have organised a series of annual national conferences, which explored all of the key issues raised including emerging models of skills training, resources to support practice delivery, user involvement, and career development and progression. Each of these conferences sought to bring together a wide range of stakeholders to both the platform and delegate list. The active participation of primary care mental health workers informed the emerging agenda.

The conference programme has now expanded to bring together the full range of professional disciplines and other stakeholders in primary care mental health across all age groups, including prison health. There is a recognition that training in primary care mental health requires all disciplines to agree core exit competencies to improve standards, particularly in the delivery of evidence-based cognitive behavioural interventions. The emergence of GPCMHWs and other health and social care workers challenges orthodox workforce planning arrangements for service delivery, and the realignment of practice roles within and across the disciplines requires a forum to examine new ways of working and highlights model innovative practice that promotes efficient team working that fully engages with service users.

\section{Service user involvement}

The earlier training commissioning interviews explored the involvement of service users and began a dialogue for identifying good practice. The level of service user integration reported in the first wave of training was very mixed. Subsequently, Nottingham Advocacy was commissioned to undertake interviews in a sample of the universities commissioned to provide training, and report back on the findings. The report recommended engaging service users in the active planning of curricula, as well as their involvement in the delivery and evaluation of course programmes. It further identified good practice for employment of service users in higher education (Gell, 2003). The service user message has subsequently been reinforced by their involvement in developing the Trent WDC framework for involving service users in training of GPCMHWs and the wider review of health and social care programme commissioning undertaken using the National Continuous Quality Improvement Tool for Mental Health Education (NIMHE North West Development Centre, 2004b; Brooker et al 2003).

\section{Funding issues in education and training}

Historically, primary care investment in mental health is highly variable and it was recognised, at an early stage, that practice level support for primary care mental health workers through both training and consolidation would differ. This has placed additional requirements on the programme leads in the higher education institutions to develop robust mentoring and supervision training systems, through a series of preparatory and ongoing workshops to brief them on their respective roles in 
supporting the integration of the workers into the practice teams and achievement of practice learning outcomes.

This exercise is demanding on programme leaders' time and inevitably incurs on-costs over and above the funding provided to primary care trusts to cover tuition fees for the postgraduate certificate programmes. Pump priming funding was identified from within the Trent WDC budget to prepare practice and clinical staff in higher education institutions.

\section{Investment in training and service delivery}

The Centre for Clinical Academic Workforce Innovation (CCAWI) at the University of Lincoln invests heavily in resources to assist graduate workers in primary care mental health to enhance their practice skills and demonstrate their potential value to primary care teams. The main focus of this investment has been the production of the interactive CD-rom toolkit launched in January 2006. Primary Care Mental Health, which is a flexible learning programme, offers a comprehensive teaching resource both to complement existing course programme delivery within the higher education institutions, and also provides the teaching materials to support the development of reconfigured blended learning programmes (CCAWI, 2006). The Centre has further invested in an updated multi-media book combining training materials with the CD-rom toolkit (Myles \& Rushforth, 2007).

A second funding stream has been directly invested in resources to support graduate workers in primary care mental health to demonstrate their potential value to primary care teams in their day-to-day practice. This has included funding to support pilot book prescription schemes and patient-led computer treatment of depression. Both initiatives seek to promote choice and widen access to mental health treatments for service users. These initiatives have also alerted primary care teams to specific ways in which primary care mental health workers can facilitate guided self-help. Primary care teams are actively encouraged to review and strategically plan for the continued development of these schemes.

The current provision of primary mental health care is highly variable across the local trust areas, and the rolespecific guidance from the Department of Health acknowledges this (DoH, 2003). Local discussions within the key partnerships reveal different views on how the graduate primary care mental health workers can complement existing provision, build upon good practice, and work with other agencies where local health and social care initiatives need a mental health presence. The commissioning of higher education training programmes sought to ensure at validation that core learning outcomes embrace the three broad areas where graduate workers may be deployed, though recognise that the emphasis on direct client work, audit and engaging with the voluntary sector will differ across primary care trusts according to local need.

The 21 post graduate certificate training programmes commissioned to date have developed curricula with broadly consistent learning outcomes and work has now commenced to develop specific exit competencies (Oates, 2005). However, there is no evidence to date to support the view that collectively all training programmes deliver students whose exit competencies in practice delivery are to a common standard other than an academic one. (HEA Psychology Network, 2007)

While the evidence base for the cognitive behavioural interventions is firm, the effectiveness of graduate primary care mental health workers has yet to be established (Lovell et al, 2003; Ekers et al, 2004). As a first step, the National Primary Care Research and Development Centre examined the characteristics of the first cohort of primary care workers, their aspirations and the perceived barriers to their practice development, and ultimately their retention within the skills mix of the mental health workforce (Harkness \& Bower, 2006). This report seeks to refine the understanding of the new workforce profile and inform future recruitment policies. However, it does not examine the effectiveness of primary care mental health workers through clinical outcome measures, specifically the cognitive behavioural functioning of the service user pre and post-treatment.

\section{Improving access to psychological therapies}

The barriers facing the GPCMHWs aiming to improve access to psychological therapies for people with anxiety and depression are mirrored in the wider challenges faced by therapists and other professional disciplines. Pivotal to delivery of an effective provision is the imperative to articulate the arguments for a major investment in 
psychological therapy services. The Improving Access to Psychological Therapies (IAPT) programme, (DoH \& CSIP, 2006) seeks to deliver on the government's manifesto commitment. Its main aims are to:

- improve individuals' well-being, satisfaction and choice

- improve access and support to maintain people in work and to help them to return to work

- develop clinical protocols to ensure clinically effective treatments are available to people in primary and community locations

- develop service models for delivering integrated, stepped care for people requiring access to psychological therapies across the spectrum of services

- reduce waiting lists for accessing psychological therapies

- develop a workforce plan for rolling out the increases in capacity tested by the pilot sites that is sustainable, realistic and affordable.

The genesis of this programme arose out of a series of reports (Department of Health, 1996; 2001b; 2004; Layard 2005), which identified evidence-based guidelines and advice on improving the delivery of psychological therapy services. The policy background is developed in further detail in a paper published by members of the IAPT Workforce Group (Turpin et al, 2006). The IAPT Workforce Group is specifically concerned with the workforce requirements arising out of the IAPT national demonstration sites and pilots and is currently addressing a series of projects, which include estimates of model workforce numbers, skills mix, competencies required to deliver evidence-based stepped care and training requirements. A number of these projects are relevant to the future prospects of primary care mental health workers.

One estimate of demand for services, (Boardman \& Parsonage, 2005 cited in Turpin et al (2006)), identifies that the number of therapists required to meet the demand of a catchment population of 250,000 people would require 62 therapists in a skills-mixed workforce which includes $8 \%$ graduate workers $(n=4.95)$. Extrapolated across the whole of England, this would estimate a target figure of 12,338 of which 987 would be graduate workers. Internal costings by the Department of Health, reported in Turpin et al (2006) estimate the number of therapists at 6,700 , with the published target of 1,000 graduate workers a matter of record in the Priorities and Planning Framework 2003-6 (DoH, 2002). The IAPT
Workforce Group recognises that the total number of therapists required and the skills mix ratio are yet to be accurately modeled.

The Department of Health and Care Services Improvement Partnership (CSIP) in collaboration with the Department of Work and Pensions have sponsored two national demonstration sites in Doncaster and Newham, which aim to test the effectiveness of providing significant increased resourcing of therapy services for common mental health problems. The report from Lord Layard (2005) signaled the determination to address the national economic burden, and the stark personal financial costs of unemployment and extended sick leave for people with anxiety and depression, and this has influenced the target client group and service models deployed. As we go to publication, the demonstration sites will publish initial outcome data. In Doncaster, graduate workers have been recruited in a case management role not only to provide signposting and guided self-help at stepped care levels one and two, but have received additional training in medication management and brief psychological interventions at level three. The interim report will provide a clearer appreciation of the competencies required to deliver effective interventions at this level, and clarification of practice interventions that deliver health and social functioning improvements to a defined population profile. The results will be of interest to commissioners planning local services seeking to clarify the role of the graduate worker, to inform the refinement of education and training programmes, and to signal the potential of graduate workers to deliver high quality care.

\section{Summary}

The development of the GPCMHW capacity has posed significant challenges above and beyond the initial education and training commissioning arrangements. Forward strategic planning recognised the potential barriers to successful implementation, for example, the costs to stakeholders and the necessity of secure funding streams to support both continued dialogue and postcommissioning activity.

The implementation plan has required flexibility. Pivotal to this has been sustained dialogue with a wide range of stakeholders and the recognition that both professional and service user organisations are well placed to work with the project management team 
towards pragmatic solutions. Overcoming barriers to implementation has required targeted funding to find bespoke solutions both determined and implemented at local, regional or at national level.

The structural financial difficulties reported by PCTs during 2005-6 have yet to be fully resolved, and workforce development budgets, including funding for training programmes, have been adversely affected across many regions in England. The move to greater local determination of clinical priorities precludes directives on priority setting from the centre. Local commissioners will have greater discretion on configuring service delivery.

Decisions on recruitment and training of GPCMHWs at a local level will require support from SHA mental health leads, and they in turn will require convincing that the case management skills of GPCMHWs are yielding a real and measurable improvement in clinical outcomes and social adjustment for service users.

The outcomes from the two demonstration sites at Doncaster and Newham will provide useful evidence to help determine the competencies required to deliver effective care at level three, inform the refinement of training programmes, and provide detailed outcome data and costings to help inform decisions on future investment in primary care mental health.

\section{Address for correspondence}

David Rushforth

Principal Lecturer National Project Manager

CCAWI

University of Lincoln

Pleasley Vale Business Park

K2, Floor 2, Mill 3

Outgang Lane

Mansfield, NG19 8RL

Tel: 01623819143

Email: drushforth@lincoln.ac.uk

\section{References}

Appleby L (2007) Mental Health 10 Years On: Progress on Mental Health Reform [online]. London: Department of Health. Available at: www.dh.gov.uk/en/Publicationsandstatistics/ Publications/PublicationsPolicyAndGuidance/DH_074241 [accessed 8 May 2007].

Boardman J \& Parsonage M (2005) Defining a Good Mental Health Service. London: Sainsbury Centre for Mental Health.
Brooker C, James A \& Redhead E (2003) National Continuous Quality Improvement Tool for Mental Health Education. York: Northern Centre for Mental Health.

Centre for Clinical and Academic Innovation (2006) Primary Care Mental Health: An Interactive Toolkit for Professionals Working with Common Mental Health Problems. Mansfield: University of Lincoln.

Crosland A \& Kai J (1998) They think they can talk to nurses: practice nurses views of caring for mental health problems. British Journal of General Practice 48 1383-1386.

Department of Health (1996) NHS Psychotherapy Services in England: Review of Strategic Policy. London: Department of Health.

Department of Health (1999) National Service Framework for Mental Health. Modern Standards and Service Models. London: Department of Health.

Department of Health (2000) The NHS Plan: A Plan for Investment, a Plan for Reform. London: Department of Health.

Department of Health (2001a) Shifting the Balance of Power in the NHS: Securing Delivery. London: Department of Health.

Department of Health (2001b) Treatment Choice in Psychological Therapies and Counselling. Evidence-based Practice Guidance. London: Department of Health.

Department of Health (2002) Planning for Health and Health Care: Priorities and Planning Framework [online]. London: DoH. Available at: www.dh.gov.uk/en/Publicationsandstatistics/ Publications/PublicationsPolicyAndGuidance/DH_4007616 [accessed 9 May 2007].

Department of Health (2003) Fast-forwarding Primary Care Mental Health: Graduate Primary Care Mental Health Workers. London: Department of Health.

Department of Health (2004) Organising and Delivering Psychological Therapies. London: Department of Health.

Department of Health \& Care Service Improvement Partnership (2006) Psychological Therapies. London: DoH. Available at: http://www.mhchoice.csip.org.uk/psychological-therapies.html [accessed May 2007].

Ekers D, Lovell K \& Richards D (2004) New ways of working and new roles in primary mental health care. Mental Health Nursing 24 (2) 8-12.

Gell C (2003) Guidance for User Involvement in Mental Health Training in Higher Education. Nottingham: Trent Workforce Development Confederation.

Goldberg D \& Huxley P (1992) Common Mental Disorders. London: Routledge.

Harkness E, Bower P, Gask L \& Sibbald B (2006) National Evaluation of Graduate Primary Care Mental Health Workers. Manchester: National Primary Care Research and Development Centre.

Higher Education Academy Psychology Network (2007) The Graduate Primary Care Mental Health Worker Programme: A View from Higher Education Training Providers. University of York: Higher Education Academy.

Kendrick T, Burns T, Freeling P \& Sibbald B (1994) The provision of care to general practice patients with a disabling mental illness: a survey of 16 practices. British Journal of General Practice 44 301-309. 
Kerwick S, Jones R, Mann A \& Goldberg D (1997) Mental health care training priorities in general practice. British Journal of General Practice 47 1383-1386.

Layard R (2004) Mental Health: Britain's Biggest Social Problem? London: Cabinet Office Strategy Unit.

Lovell K, Richards D \& Bower P (2003) Improving access to primary care mental health: uncontrolled evaluation of a pilot self-help clinic. British Journal of General Practice 53 133-135.

McCormick A, Fleming D \& Charlton J (1995) Morbidity Statistics from General Practice Series MB5, 3. London: HMSO.

Murray C \& Lopez A (eds) (1996) A Comprehensive Assessment of Mortality and Disability from Diseases, Injuries and Risk Factors in 1990 and Projected to 2020. The Global Burden of Disease and Injuries Series. Volume 1. Cambridge, MA: Harvard University Press on behalf of the WHO and World Bank.

Myles P \& Rushforth D (2007) Primary Care Mental Health. A Complete Guide to Primary Care Mental Health: The Essential Reference and Learning Resource. London: Robinson.

NIMHE North West Development Centre (2004a) Enhanced Service Specification for Depression under the New GP Contract. Hyde: National Institute for Mental Health in England.
NIMHE North West Development Centre (2004b) Primary Care Graduate Mental Health Workers - A Practical Guide. Hyde: National Institute for Mental Health in England.

Oates M (2005) London Graduate Primary Care Mental Health Worker. Pan-London project report, September 2003-August 2005, appendix 7. London Development Centre.

Plummer S (1997) A controlled comparison of the ability of practice nurses to detect psychological distress in patients who attend their clinics. Journal of Psychiatric \& Mental Health Nursing 4 221-223.

Rushforth D (2004) The Graduate Primary Care Mental Health Worker - A Progress Report. Mansfield: Trent Workforce Development Confederation.

Turpin G, Hope R, Duffy R, Fossey M \& Seward J (2006) Improving access to psychological therapies: implications for the mental health workforce. Journal of Mental Health Workforce Development 1 (2) 9-18.

Workforce Action Team (2001) Adult Mental Health: National Service Framework and the NHS Plan: Workforce, Education and Training [online]. London: Department of Health. Available at: www.dh.gov.uk/en/Publicationsandstatistics/Publications/Public ationsPolicyAndGuidance/DH_4009159 [accessed 9 May 2007]. 